\title{
A phenomenological evaluation of a hybrid model of problem based learning for multidisciplinary healthcare practitioners
}

Dr Catherine Hayes

University of Sunderland, UK

Prof. Mark S. Davies

University of Sunderland, UK

\section{Abstract}

This study reports on the evaluation, using a phenomenological approach, of a hybrid model of problem based learning (PBL), implemented with a cohort of fifteen students. Semi-structured interviewing provided an interpretive basis for the lived experience of teaching and learning in the context of a Masters Degree programme designed specifically for multidisciplinary postgraduate healthcare education.

The findings point towards a differentiation of attitude from behaviour and are grouped into three themes of 'Professionalism and the Value of Character', 'Perceived Cognitive Development and Meaningful Learning' and the 'Situatedness of Learning and Knowledge Transfer'. It was perceived by students that professionalism could be learned through the process of PBL, although they did not necessarily feel familiar or comfortable when this process was new to them. They perceived the major benefit of using a hybrid model of PBL as a teaching strategy was that it afforded all students in the cohort a means of being valued in their contribution to the sessions and in their wider contribution to a multidisciplinary workforce. The significant degrees to which both interprofessional learning and the adoption of a multidisciplinary approach had impacted upon student engagement were the two most salient outcomes of the study.

Keywords: problem based learning; health; phenomenology; hybrid model; interprofessional learning; multi-disciplinary learning; Masters; lived experience. 


\section{Introduction}

Problem based learning (PBL) approaches are well-established in healthcare and medical education. However, their use in programmes that cross disciplines is scant and to our knowledge no evidence exists on the evaluation of hybrid educational models that aim to facilitate multi-disciplinary approaches in Higher Education (HE).

This study evaluates a hybrid model of PBL designed and implemented in a MSc in Advanced Clinical Practice programme. This hybrid model is categorised as a merge of Situated Learning (Lave and Wenger, 1991) and PBL (Dolmans et al., 2005). Since onethird of the programme's credits constitute a practice-based placement, the use of Situated Learning was a valuable adjunct to PBL since it allowed students to learn in the context of patient-centred care.

\section{Aim}

The overall aim of this study was to evaluate the educational experiences of students who had experienced the hybrid model of PBL. By illuminating their experiences it was hoped that how valuable the hybrid model of PBL was to the process and outcomes of a multidisciplinary approach to healthcare education could potentially be established. Accounting for this lived experience involved acknowledging the previous educational experiences that students had and also considered the relationship between their intellectual development and the best way to tailor individual learning pathways.

\section{The programme}

The MSc in Advanced Clinical Practice is a full-time, 12-month programme for graduate healthcare professionals. The fundamental basis of the programme is to provide the healthcare arena with practitioners capable of performing a strategic and needs-led role both within the teams in which they work and in capacity building between professional disciplines in patient-centred care. The programme consists of five modules, three of which are 'taught', and is structured so that all taught sessions are delivered to all students. The 'non-taught' modules are a placement and a research project. Teaching staff act as facilitators of students' learning and are trained in-house in the hybrid PBL 
approach. The cohort reported on here comprised fifteen students. The curriculum moves beyond traditional approaches to postgraduate healthcare educational provision and hinges directly on the facilitation of a 'community of practice' (Lave and Wenger, 1991). The move towards capacity-building lends itself to a strategic pedagogy that enables collective learning yet individual assessment to take place. It is hoped that this approach to learning might promote critical reflexivity rather than the one-dimensional approach to reflective practice traditionally adopted at this level of education (Westwood et al., 2008).

Since the context of learning matters, 'Situated Learning' (Lave and Wenger, 1991) is implemented in the curriculum. Situated Learning has evolved in recent years to encompass how positive learning experiences are closely linked to the processes of regular human interaction. For postgraduate students in patient-centred care, education can be regarded as a shared endeavour (Pasquinelli, 2011). The notion of context has been developed by Lave and Wenger into three characteristics of 'context specificity', identified by:

- Community - defined here as students' inclusion in their cohort and 'belonging' to a healthcare profession;

- Domain - specified as the clinical area within which students are experiencing teaching, learning and assessment;

- Practice - defined as their contribution to patient-centred care.

Instead of engineering acquired knowledge, skills and behaviour in a regimented manner through the curriculum, these are allowed to emerge through participation in a flexible (negotiated) assessment system driven by the processes of teaching, complemented by the opportunity for collaborative and social learning (Dirkx,1997).

\section{Problem based learning}

Throughout the programme, short case scenarios are used to initiate and guide the process of learning at postgraduate level. Emphasis is placed on the gaps that students discover in their knowledge and skills, and how to bridge these gaps with new knowledge, new understanding and modified behaviour patterns. This particular PBL approach aims to enable students to discover and learn for themselves through facilitation by experienced 
tutors (Barrett, 2010). The system essentially replaces traditional didactic teaching methods and enables learning through the creation of a cohesive learning group. Each element of the programme consists of a series of clinically-related problems, which students use to define their specific study objectives on a day-by-day basis. Students work collaboratively in developing their understanding of advanced clinical practice.

Using a seminal and identified approach to the process of PBL (Moust et al., 2001) students work collaboratively in developing their knowledge and understanding of advanced clinical practice and how this knowledge applies to practice. Students' induction to the programme incorporates time dedicated to teaching the process of PBL in practice, allowing them to practice the technical process before the start of the programme. Students begin with relevant clinical problems. As a group, facilitated by a specialist in the discipline of the case within which they are working, the students first establish how much they already know and understand of the element of advanced clinical practice in question. They then define what they need to learn in order to fully understand the element and its associated problems that they encounter in everyday clinical practice, by formulating learning objectives (Moust et al., 2001). What students study is, therefore, more clearly defined by the needs of their own individual work, supplemented by robust learning opportunities, including the consideration of problem-based scenarios. Robust here refers to the fact that all cases students worked on were constructively aligned in terms of learning domains, which in turn were constructively aligned to the mechanism of assessment.

\section{How learning drives the process of assessment}

Learning is enhanced by allowing students to negotiate how they fulfil individual learning outcomes at module level. The challenges presented in developing the programme were significant since to teach people from different healthcare disciplines together, emphasis had to be shifted from assessment processes to assessment outcomes. The content of the assessment is constructively aligned with the domain of learning (as previously outlined) and the nature of the evidence they wish to submit as a portfolio to demonstrate the achievement of learning outcomes. This process demonstrates the purposefulness of their work to their field of clinical practice and also illuminates the benefits of adopting the hybrid 
PBL approach in terms of being able to individually tailor not just the teaching and learning processes across the programme, but the assessment process as well.

\section{Methods}

\section{Design and rationale of the approach}

In the last fifty years a wealth of research has demonstrated the convergence of shared experience and interpretation of experience that can be captured by the phenomenological tradition (see Pringle et al., 2011 for review). Debates have emerged around the ability of interpretive phenomenological approaches to demonstrate relevance in the development of new patient/practitioner experiences in healthcare provision (e.g. Kuller, 2007). Often it is the question of whether or not consistency between the philosophical origin and its application to methodological execution exists (e.g. Knox, 2004). Following formal institutional ethical approval, this study adopted an interpretive method, where emphasis was placed directly on accessing the lived experience of participants through the use of semi-structured interviews and the formal evaluation questionnaires regarding the MSc. In an attempt to gain access to and make sense of the lived experience of postgraduate healthcare students, we used a basic modification of the phenomenological method originally developed by the Duquesne School, first articulated and demonstrated by Giorgi and further developed by Stevick-Colaizzi-Keen as documented by Moustakas (1994). This is a relatively reductionist approach to distilling themes and perspectives of the lived experience of the students.

\section{Sampling and data collection}

All fifteen students (who were allocated a pseudonym to preserve confidentiality throughout the study) completed a questionnaire that contained only four items, as follows.

1. Tell us about the kind of teaching and learning experiences you have had on the MSc programme here at the university.

2. How is it different to what you have experienced before?

3. What will you take away from this experience?

4. Tell us about any positive and negative experiences of your time on the programme in relation to those teaching and learning experiences. 
We adopted, in accordance with a phenomenological approach, a position of 'conceptual silence' (Stones, 1988), or naivety, and bracketed off pre-existing suppositions about what the participants might disclose. This involved suspending any ideas we might have about the thoughts and feelings of the participants. Though we are confident through reflection that this was achieved, we, of course, cannot be sure at an interpretive level. The questions were designed to encourage respondents to think deeply and critically about their experience of the hybrid PBL approach. We deliberately avoided questions that (a) would lead to a listing of answers and (b) would afford respondents the opportunity to become overly theoretical since we wanted to capture and access their personal livedworld, the concrete experience of their educational pathway.

The questionnaire acted as a rough sieve for selecting a smaller group of respondents (ten) to act as participants in in-depth interviews; and provided a framework for those interviews. Ten was purposively selected because this is optimal for a phenomenological investigation (Moustakas, 1994). We selected the ten respondents on the richness of their responses (i.e. the students who had been most forthcoming in sharing detailed knowledge of their individual experiences of the programme). The demographics of the participants were significant to the research since we wished to build a picture of the diversity of the people we had interviewed in terms of their professional identities, but we did not deliberately seek specific racial, cultural or gender representation. Nor did we seek to relate demography to these professional roles. In keeping with the fact that phenomenology seeks to capture the lived experiences of individuals from their perspectives alone, we felt it appropriate to list below the important attributes of profession, race and gender. The sample comprised:

- A black male doctor,

- A white male healthcare manager,

- A white male podiatrist,

- A white female podiatrist,

- A white female orthopaedic ward manager,

- Two white female community healthcare practitioners,

- A white male biomedical scientist,

- A white female biomedical scientist,

- A white female midwife. 
Each of these participants was then interviewed, with the questions varying according to the responses to the questionnaire. Questions typically asked for clarification or more detail of opinions and perceptions. Interviews were audio recorded and transcribed in full. The transcript of each interview was then given to each respective participant for checking of respondent (content) validity to ensure that the transcript accurately represented the dialogue between researcher and participant. In three cases, some additional follow up questioning due to a lack of clarity of expression within the interviews was necessary and was obtained using a further brief interview, which again was transcribed and checked with the participant.

\section{Data analysis}

All the analysis was undertaken by one person for consistency. The transcripts were examined for commonality of emergent themes between participants in the study. This produced an annotated descriptive and summarised version of the raw data, in accordance with the framework analysis advocated by Ritchie and Spencer (2004). In terms of developing key themes and perspectives, their framework analysis involves five clearly identifiable phases, which the researcher found logical to execute.

\section{Phase 1: Familiarisation with the raw data}

This is the process that allowed the researcher involved in this phase of the research to become 'at one' with the transcribed data collected. It also allowed field notes and the few observational comments made during the interviews to be integrated alongside the transcribed interviews, enabling contextualisation and framing of their significance. Through this immersion it was possible to gain an overview of the data and begin to identify the repeated themes or perspectives. For students where too much raw data had been collected it was possible to be selective in what we included, although focus on incorporating a representative sample from all participants was a key aim.

\section{Phase 2: Identifying a thematic framework within which to work}

This was heavily reliant on the ability to move beyond purely being familiar with the data transcriptions and to fully recognise the themes and perspectives emerging from within 
them. When the broadest perspectives were identified they were used to filter the transcripts and develop specific themes. Themes were developed at this stage according to the framework analysis tool of Ritchie and Spencer (2004). Vigilance was necessary in recognising any potential for ideas the researcher might already have about the general perspectives that emerged. Nonetheless, Ritchie and Spencer (2004) acknowledged that since investigation of this nature is likely to have been designed around a particular issue (in this case our evaluation of the curriculum), this will potentially direct the development of the thematic framework. Intuitive processes were used to make value judgements based on meaning, the contextualisation of evidence, and the interconnectedness of key factors identified.

\section{Phase 3: Indexing themes and perspectives}

Specifically identified themes for indexing purposes were decided upon here. Manually handling the data, instead of using a software package, gave a greater sense of perspective on them.

\section{Phase 4: Charting results}

The data were then taken out of context and given in diagrammatic form that contained headings and subheadings developed during phase 3. Ordering of the data was very important here, since if it were not logical and sequential any clear meaning might be lost or appear nebulous.

\section{Phase 5: Mapping and interpreting}

Here the researcher constructed a diagram of the phenomenon under investigation (the evaluation of the curriculum). We then compared this diagram with that produced in phase 4 to contextualise the themes and perspectives that had emerged. Any inference drawn at this stage had to be a true representation of the value systems, perceptions and beliefs of the participants in our research, i.e. their experience of learning via a hybrid model of PBL.

A final validating step of content was achieved by returning to the participant and asking whether the description produced was a trustworthy and authentic account of the original experience (Pope et al., 2007). In all cases no amendments were required. 


\section{Analysis of findings and discussion}

From the transcripts three dominant themes emerged and were further developed into a theoretical interpretation of findings, which merged the phenomenological experiences of students into a tangible base for the development of theoretical perspectives of significance from the study, which had not been previously identified from the published literature. Again, these interpretations were validated by students using the process described above.

The themes, and sub-themes, were as follows. Under each section is a report of the interpretation (phase 5 ) of what students expressed. We give quotations from students to provide an insight into their overall experiences of the programme across the dominant theoretical themes that emerged.

\section{Professionalism and the Value of Character}

\section{Subtheme One: Differentiating attitude from behaviour}

The interpretation was that experience of the curriculum enabled students to differentiate between the concepts of attitude and behaviour, and that this aided the development of their professionalism. Social learning was seen as being central to this and professional engagement in the sessions became a social norm rather than being driven by staff.

\section{Subtheme Two: Interprofessional capacity building}

It was interpreted that the hybrid PBL model had broken down barriers between different healthcare disciplines and that facilitated discussions allowed students to articulate not only an evidence base but also how they applied this evidence base to practice. It was also interpreted that in terms of social integration in the group, as might be expected, individual personalities and characters were very relevant to the overall group dynamics. These group dynamics facilitated collaborative learning and the transferrable skills students learned while taking part in this collaborative learning were interpreted as being highly relevant to the workplace. 


\section{Subtheme Three: The situated context of learning and experiential learning} It was interpreted that by adopting the hybrid model of PBL, students had been enabled to internalise knowledge and use this as a tool in their own professional development.

\section{Perceived Cognitive Development and Meaningful Learning}

\section{Subtheme One: Student entry behaviour}

It was interpreted that the perceptions students held about their cognitive development and their conceptualisation of the meaningfulness of learning were closely linked to their educational experience on entry to the programme.

It was considered that their self-perceived cognitive development related directly to their current educational standing in an academic community. Those students who had not been in formal education for an extended period (several years) appeared to respond more flexibly to the introduction of new approaches to teaching and learning, whereas those who had recently been undergraduates found the transition from a didactic teaching approach more of a challenge.

\section{Subtheme Two: Applying knowledge to practice}

Two students felt that their historical roots of learning had revolved around memorising facts and then attempting in practice to apply the things they had memorised without any process of facilitation. Others though appreciated the diverse range of topics that the hybrid PBL model permitted. From this point of view it built capacity within and between professional healthcare disciplines.

The variety of topics covered in lectures - sometimes not relevant to your own profession - but this gives you an insight to your fellow colleagues' professions. (Anna, Podiatrist)

It was interpreted that the hybrid model of PBL facilitated them in engaging with the translation and application of knowledge to practice. In this sense, the hybrid model of PBL had not allowed them to go down the path of rote learning. 


\section{Subtheme Three: Motivation to learn}

It was considered that the hybrid PBL model had motivated students to learn and that this linked directly to the ability of individual facilitators in helping to develop metacognitive skills; thus the skill of facilitation is crucial to the success of our model of PBL. 'Meaning making' was facilitated, where the facilitator had identified the significance of what the students had internalised and reflected upon. One student in particular reflected deeply on the impact of the hybrid PBL model relative to other programmes of study he had experienced:

Never in my life have I been exposed to such a huge range of obtainable knowledge in a short period of time and not only been undaunted by it, but excited and eager to want to know it all. (Derek, Bioscientist)

The process of meaning making was not simply related to straightforward solutions to the PBL cases used in teaching sessions, but to how the solution was arrived at and how key generalisations on the transferability of knowledge might be made or inferred. Bridging the theory-practice gap was significant and we interpreted that students felt able to both build professional relationships and build capacity within and between clinical healthcare disciplines.

\section{Subtheme Four: Skill acquisition}

It was interpreted that there was a need to recognise students' individual starting points in learning development. In relation to this it was considered that engagement with the hybrid PBL approach enabled them to identify their own specific learning needs and had facilitated them in setting their own means of fulfilling learning outcomes across the programme. Students' explicit engagement with affective domain learning had a significant impact on both their sense of self-perception and their regard for other professional healthcare disciplines with which they had formerly not been familiar. The degree of freedom that the hybrid PBL model afforded students was something one student found particularly empowering:

Unlike other courses I have attended such as my degree, on this course I enjoy the freedom to learn what I wish, explore as far as I want and it will still be relevant in one way or another. My degree would show me want I need to learn and understand but 
exploration too far into an interesting matter would mean neglecting concentration and effort on the areas I am to be assessed, whereas with this course it is as if I am being told, 'The world is yours to learn, indulge your interests. Go forth, create, discover and here is some things to think about and ways to make sure you're doing it right along the way'. (Julia, Biomedical Scientist)

It was also interpreted that the intentional observation by the facilitator of their cognitive performance was helpful in allowing students to analyse and make meaning of the cases with which they were engaging. In conjunction with this, one-to-one tutorial provision was useful in consolidating the process of meaning making. Also, the development of metacognitive strategies had to be facilitated and this played a role in students' learning and was a motivating factor within it.

\section{The 'Situatedness' of Learning and Knowledge Transfer}

\section{Subtheme One: Associationism}

The researcher interpreted and refined the concept of 'associationism' in terms of students expressing their ability to transfer their knowledge base to practice. Knowledge acquisition was important, but it was interpreted that students also valued the focus on professionalism the programme had given them. The placement element of the programme had allowed them to work within their own scope of practice, yet explore the parameters that existed between professions. The programme had changed how students would seek to build relationships with professionals from other disciplines that they had never deemed of any relevance to their own. Learning was driven by previous connections or associations to pre-existing knowledge. Unless knowledge gained in the context of the classroom advanced their already competent practice, then it would not be cognitively retained for long enough to be internalised and then reactivated at a later stage.

\section{Subtheme Two: The creation and facilitation of knowledge}

It was interpreted that where sessions were not constrained by formality, students felt at liberty to experiment with knowledge or push the boundaries of their own understanding, particularly in the placement module. This was facilitated by a range of healthcare staff: 
Working and learning beside a variety of allied health care professionals gave a depth of knowledge that otherwise l'd never have experienced. (James, Musculoskeletal Podiatrist)

This was, however, counterbalanced by the need to legitimate newly-created knowledge, especially where they perceived this to have been developed within the group. It was extracted that the hybrid PBL approach meant students could not be passive in their approach to learning across the programme and this was significant when it came to the creation of new knowledge. It was also rationalised that where there was little pre-existing knowledge of a topic of study, their perception of the assessment process was that it was less flexible and that assessments were more difficult than in other modules. This happened despite the process being identical in all modules of the programme. It was also evident that the hybrid PBL approach allowed them to learn far more than previously grow, emotionally in their ability to relate to other professions, and enhance their professional capacity to engage with others from different backgrounds.

\section{Subtheme Three: Legitimacy of knowledge}

It was considered that the hybrid model of PBL made students think about the knowledge that was created in the sessions and the legitimacy of that knowledge. The process of how and by whom the sessions were facilitated were critical factors in determining the knowledge gained. The programme created a forum where the students could establish and extend the parameters of their social norms within an atmosphere of relative trust, and the relationship between the facilitator and the cohort was significant. Historically students had been left feeling intimidated, contained, and unable to either create or take ownership of any knowledge from teaching sessions because of the sense of 'power' they perceived their former teachers possessed. It was also interpreted that they no longer felt they were expected to absorb knowledge and then regurgitate it at a later stage, and because of this they could then usefully define what they both wanted and needed to learn, as expressed by one student who said:

Learning the research process and philosophy in greater depth and having the knowledge and skills to rationalise why one method or philosophy is best suited to particular research. (Claire, Occupational Health Nurse) 
The hybrid model of PBL gave them the opportunity to apply their knowledge within the context of their workplace roles and settings. Cognitive meaning from the specific subject areas was interesting, but it was considered that it was the transferrable skills and enhanced critical thinking skills that they gained from the programme that were valued most highly. We concluded that the notion of authentic learning, what constitutes authentic real life problems, and the value of connections between tacit knowledge and applied practice were of fundamental value.

\section{Transcending themes}

There was an interrelationship between the three themes, though the notion of 'learning' was central to all three. Meaning making was dependent on both the individual starting point of intellectual development as defined by Perry (1981) and by the integration of professionalism, knowledge and skills through the programme. Transcending the three themes, three theory-related areas were identified, as follows:

\section{Facilitation of learning}

The reciprocal relationship between the learners and the person facilitating the hybrid model of PBL was important to students and this raises the issue of the level of expertise necessary to facilitate sessions. Emphasis is placed on the creation rather than the consumption of knowledge, though the process of facilitation and the relevance of knowledge produced, and its application to practice, is also important.

Having the opportunity to apply all the newly found skills to a research project with the valuable support of a supervisor via tutorials was a really positive part of the programme. (James, Podiatrist)

\section{Associationism}

Although there is no single theoretical stance termed 'associationism', it has a long tradition in experiential learning and the acquisition of knowledge, going back as far as Aristotle (Ackrill, 2010). This study has highlighted the need for consideration of key features of associationism, which are that all ideas can be reduced to a simplistic level, 
built upon the connections of knowledge already established as part of their lived experience (Poikela, 2005). This was reinforced by one student who said:

To be honest, I cannot think of anything that can be considered 'bad' about this course. Some things have not been in my style of learning, the way I would normally enjoy them most or as easy to grasp, but I have started to understand why things have been done the way they have. It is as if by being educated in the processes of the importance of being critical, being philosophical and being methodical, I have started to see reason in all things and understand were the logic lies. So even in aspects of the course not ideally suited to me, like others I won't foolishly and unreasonably brand them as 'bad', I alternatively think of it as an opportunity to learn and experience things in a different way. (Derek, Bioscientist)

Associationism in the context of this study can be seen as a direct attempt by students to reconstruct and engage existing intellect with the least possible engagement with educational theory - something that social learning space positively enhances (O'Rourke and Kahn, 2005). For the purposes of this study, social learning space can be defined as an environment which is conducive to learning, away from the classroom, that contains equipment to facilitate informal study. Associationism also serves to reinforce the notion that the addition of more complex ideas, cognitive strategies and connections to the body of knowledge, is one way in which new knowledge is created. This is an integral part of social constructivist approaches to education, consistent with the hybrid model of PBL adopted here. One student commented:

We have a great group of mixed disciplines which is friendly and provides a good environment for discussion and learning. This is one of many attractions and it is beneficial to view subjects from different viewpoints and although I initially felt daunted about embarking on a Masters I am motivated to complete. (Alice, Ward Manager)

The notion of professionalism as a developmental activity was highlighted by students and, through their engagement with the teaching and learning processes across the programme, they considered that they were better equipped to evaluate their stage of professional development. One consideration, however, must be that their self-perception of 'where they were' was relative to the other members of the cohort. It was not 
necessarily benchmarked against their own achievements to date, and it was the degree of critical reflexivity and reflection on lived experience that allowed them to further develop their skills of professionalism. Using teaching and learning to drive purposeful mechanisms of assessment has been a focal point of discussion by educational theorists for several years (e.g. Savin-Baden, 2004). Evidence came from one of the students describing the relevance of the programme to practice:

A great course to deepen my knowledge in general but in topics that I'm really interested in, whilst being valuable to my future practice. (Sarah, Nurse Practitioner)

\section{Meaning Making and the Legitimacy of Knowledge}

Barrett (2004) engaged at length with the need to consider social learning opportunities, and the findings from the present study are consistent with the notion that the discourse that underpins the PBL facilitation is highly significant to the outcome of the experience of being taught. The hybrid PBL model also highlighted for some students mechanisms of overcoming learning disability:

It has rekindled my passion for wanting to pursue a $\mathrm{PhD}$ and has helped me to overcome my dyslexia in such a way that I now feel my thoughts are more easily transferred to writing and I am more able to articulate my passions and feelings like never before. (Derek, Bioscientist)

The students showed a dichotomy of thinking around how this impacted upon the ability to improve the means by which they developed not only an awareness of their own professionalism but also the further extension of it within the context of their workplaces. Some thought that professionalism was an inherent part of personality, while others thought professionalism was an acquirable attribute. Social learning facilitated a means of bridging who they were professionally with who they were personally, consistent with Severiens and Schmidt (2009). This was seen as being very different by students, one of whom said:

New and innovative teaching methods which help you learn in a new and exciting way. I will always look back fondly on my experiences. (James, Podiatrist) 
Daniels' (2008) commentary on the work of Lave and Wenger and Vygotsky is of obvious significance to this study. Lave and Wenger (1991) advocated learning best within the context of 'communities of practice' and Vygotsky (1978) provided an overview of the 'scaffolding' of knowledge. However, it is the integration of the hybrid model of PBL that raises the issues of how social learning can be integrated across specific domains of learning and in particular the notion of constructive alignment. Also significant in the context of higher education provision for postgraduate healthcare students is the issue of international education provision and cultural diversity (Eaton et al., 2011). One student on the programme expressed his opinion of how the programme functioned to integrate people culturally and across healthcare disciplines when he stated:

The integration of students from a wide variety of health care disciplines has given me the chance to learn about other professions at a greater level than I would learn about them in any other way. (Derek, Bioscientist)

The emergent themes from this study highlight the need to examine the concept of 'realworld relevance' and how this is designed in the context of a hybrid PBL approach. This is a finding that consolidates the work of Raine and Symons (2005) who studied PBL in physics education in the compulsory sector. In order to be authentic, the cases with which students work ought to match the actual tasks as closely as possible (Schmidt et al., 2011).

\section{Conclusions and implications for practice}

The significant degrees to which both interprofessional learning and the adoption of a multidisciplinary approach had impacted upon student engagement were the two most salient outcomes of the study. These have a direct implication to pedagogic practice. Both promote consideration of how social constructivist perspectives in education can be used as a means of best facilitating affective domain learning in the process of constructive alignment. This is significant in the scope of developing professionalism and the processes of how students interact with one another in a formalised learning environment, and how this translates into healthcare practice. How patient-centred care can be optimised by enabling healthcare practitioners to develop their knowledge and skills provides a valuable opportunity for educators to develop curricula that incorporate opportunities for 
interprofessional learning. The issue of whether professionalism can be taught remains a significant debate in the light of this study. It would appear that it was not what was taught that contributed most to the notion of generic skill transferability, but rather how the teaching and learning process was formalised so that all students had to contribute equally to the creation of new knowledge and the consolidation of that which pre-existed. An ongoing issue for discussion remains the legitimacy of knowledge created within the context of any PBL curriculum.

Building curricula around shared visions of improving assessment, diagnosis and management of patients has become a keystone in facilitating collaborative working. Although this is a small scale study from the perceptions of students, there is much potential for our hybrid model to contribute to developing effective practitioners. In particular, the building of capacity within and between healthcare disciplines in the context of patient-centred care through a shared understanding of the differentiation, and blurred edges, of disciplines.

\section{Acknowledgements}

We are grateful to two anonymous reviewers for their valuable comments.

\section{References}

Ackrill, J.L. (2010) Essays on Plato and Aristotle. Oxford: Oxford University Press.

Barrett, T. (2004) 'Researching the dialogue of PBL tutorials: a critical discourse analysis approach,' in Savin-Baden, M. and Wilkie, K. (eds.) Challenging research into problem based learning. Buckingham: Open University Press, pp. 93-102.

Barrett, T. (2010) 'The problem-based learning process as finding and being in flow', Innovations in Education \& Teaching International, 47(2), pp. 165-174.

Daniels, H. (2008) Vygotsky and research. London: Taylor and Francis. 
Dirkx, J.M. (1997) 'Nurturing the soul in adult learning', New Directions for Adult and Continuing Education, 74, pp. 79-88.

Dolmans, D.H.J.M., De Grave, W., Wolfhagen, I.H.A.P. and Van der Vleuten, C.P.M. (2005) 'Problem-based Learning: future challenges for educational practice and research,' Medical Education, 39(1), pp. 732-741.

Eaton, D.M., Redmond, A. and Bax N. (2011) 'Training healthcare professionals for the future: internationalism and effective inclusion of global health training', Medical Teacher, 33(7), pp. 562-569.

Knox, K. (2004) 'A researcher's dilemma - philosophical and methodological pluralism', Electronic Journal of Business Research Methods, 2(2), pp. 119-128.

Kuller, L. (2007) 'Is Phenomenology the best approach to health research?', American Journal of Epidemiology, 166(10), pp. 1109-1115.

Lave, J. and Wenger, E. (1991) Situated learning: legitimate peripheral participation. Cambridge: Cambridge University Press.

Moust, J.H.C, Bouhuiijs, P.A.J. and Schmidt, H.G. (2001) Problem-based learning. A student guide. Groningen: Walters-Noordhoff.

Moustakas, C. (1994) Phenomenological research methods. Thousand Oaks, CA: Sage, pp. 16-38.

O’Rourke, K. and Kahn, P. (2005) 'Understanding enquiry-based Learning,' in Barrett, T., Mac Labhrainn, I. and Fallon, H. (eds.) Handbook of enquiry and problem-based Learning; Irish case studies and international perspectives. Galway: AISHE and NUI Galway, pp. 36-45.

Pasquinelli, E. (2011) 'Knowledge- and evidence-based education: reasons, trends, and contents', Mind, Brain, and Education, 5(4), pp. 186-195. 
Perry, W.G. (1981) 'Cognitive and ethical growth: the making of meaning,' in Chickering, A.W. and Associates (eds.) The modern American college. San Francisco: JosseyBass, pp. 76-116.

Poikela, S. (2005) 'Learning at work as a tutor: the processes of producing, creating and sharing knowledge in a work community,' in Poikela, E. and Poikela, S. (eds.) PBL in context: bridging work and education. Tampere: Tampere University Press, pp. 177-195.

Pope, C., Ziebland, S. and Mays, N. (2007) 'Analysing qualitative data', in Pope, C. and Mays, N. (eds.) Qualitative research in health care. $3^{\text {rd }}$ edn. Oxford, UK: Blackwell Publishing Ltd., pp. 63-81.

Pringle, J., Hendry C. and McLafferty, E. (2011) 'Phenomenological approaches: challenges and choices', Nurse Researcher, 18(2), pp. 7-18.

Raine, D. and Symons, S. (2005) 'Experiences of PBL in physics in UK higher education,' in Poikela, E. and Poikela, S. (eds.) PBL in context: bridging work and education. Tampere: Tampere University Press, pp. 41-46.

Ritchie, J. and Spencer, L. (2004) 'Qualitative data analysis for applied policy research', in Bryman, A. and Burgess R.G. (eds.) Analysing qualitative data. London: Routledge, pp. 173-194.

Savin-Baden, M. (2004) 'Understanding the impact of assessment on students in problem based learning', Innovations in Education and Teaching International, 41(2), pp. 221-233.

Schmidt, G., Rotgans, J. and Yew, E. (2011) 'The process of problem-based learning: what works and why', Medical Education, 45(8), pp. 792-806.

Severiens, S. and Schmidt, H. (2009) 'Academic and social integration and study progress in problem based learning', Higher Education, 58(1), pp. 59-69. 
Stones, C.R. (1988) 'Research; toward a phenomenological praxis', in Kruger, D. (ed.) An introduction to phenomenological psychology. $2^{\text {nd }}$ edn. Cape Town: Juta, pp. 141156.

Vygotsky, L.S. (1978) Mind in society. Cambridge, MA: Harvard University Press.

Westwood, O.M.R., Leinster, S.J. and Weinberg, J.R. (2008) 'A healthcare curriculum for the 21st century: time for flexibility?', Journal of the Royal Society of Medicine, 101(3), pp. 59-62.

\section{Author details}

Catherine Hayes is qualified in podiatric medicine and has worked in the context of learning and teaching in higher education, with a particular focus on multi-professional learning for healthcare practitioners. Catherine is a Founding Fellow in Podiatric Medicine of the Royal College of Physicians and Surgeons (Glasgow), a Fellow of the College of Podiatric Medicine and General Practice (London) and a Senior Fellow of the Higher Education Academy.

Mark S. Davies is a biologist with a large portfolio of activities relating to learning and teaching in higher education. His research in education concerns formulating strategies for student retention, and the definitions and functions of assessment. He is a National Teaching Fellow and Principal Fellow of the Higher Education Academy. 